\title{
Laparoscopic treatment of congenital choledochal cyst and hepaticojejunostomy with extracorporeal Roux-en-Y anastomosis: technical aspects and early experience with three cases
}

\author{
Mario Lima, Tommaso Gargano, Giovanni Ruggeri, Francesca Destro, Michela Maffi \\ Department of Pediatric Surgery, S. Orsola Malpighi Hospital-University of Bologna, Bologna, Italy
}

\begin{abstract}
Choledochal cyst (CDC) is a congenital dilatation of the extra and/or intrahepatic bile ducts and it is a rare condition in western countries. Classical treatment consists of cyst excision and hepaticojejunostomy. The first case of a laparoscopic CDC excision was described in 1995 and since that time an increasing number of institutions have adopted this technique, with good success. We describe our early experience of 3 cases of CDC treated with laparoscopic approach. We used a $10 \mathrm{~mm}$ umbilical port for the camera, and four 3-5 mm operative ports. We performed the laparoscopic removal of the cyst and gallbladder, videoassisted preparation of the Roux-en-Y loop and laparoscopic hepaticjejunostomy. No post-operative complications occurred. Laparoscopic excision of CDCs has been supposed to give better observation, a better cosmetic result, potentially less postoperative pain, and a shorter recovery. The main argument for performing an extracorporeal anastomosis is that it decreases the operative time. We recommend caution to prevent injury to the pancreatic duct and biliary structures during dissection and anastomosis. Lifelong surveillance is mandatory, even after resection of the choledochal cyst.
\end{abstract}

Correspondence: Tommaso Gargano, Department of Pediatric Surgery, S. Orsola Malpighi Hospital-University of Bologna, via Massarenti 11, 40138 Bologna, Italy.

Tel: +39.051 .2144984 - Fax: +39.051 .2143651 .

E-mail: tommaso.gargano2@unibo.it

Key words: Choledochal cyst; Laparoscopy; Pediatric surgery.

Contributions: ML and GR performed all the surgical procedures; TG, FD and MM, conceived and designed the study; FD wrote the first draft of the manuscript; MM contributed to the writing of the manuscript; ML and TG made critical revisions and approved the final version. All authors reviewed and approved the final manuscript.

Conflict of interest: the authors declare no potential conflict of interest.

Received for publication: 21 December 2015.

Accepted for publication: 1 June 2016.

This work is licensed under a Creative Commons Attribution NonCommercial 4.0 License (CC BY-NC 4.0).

@C Copyright M. Lima et al., 2016

Licensee PAGEPress, Italy

La Pediatria Medica e Chirurgica 2016; 38:125

doi:10.4081/pmc.2016.125

\section{Introduction}

Choledochal cyst (CDC) is a congenital dilatation of the extra and/or intrahepatic bile ducts that causes various hepatobiliary and pancreatic disorders. CDC is more prevalent in Asian countries than in western countries.1,2 Laparoscopic cyst excision and hepaticojejunostomy for children with $\mathrm{CDC}$ have become feasible and popular recently.,4 Taking in consideration scarcity of cases in Italy, we present our early experience with three cases of type I CDC, which were operated by laparoscopic cyst excision and hepaticojejunostomy with extracorporeal Roux-en-Y anastomosis.

\section{Case Report \#1}

A 14-month old girl was referred to our hospital for recurrent vomit and abdominal pain. Her medical history had always been uneventful. On admission we performed laboratory tests (white blood cell 11.480/mL, gamma glutamyl transpeptidase $337 \mathrm{U} / \mathrm{L}$, alkaline phosphatase $1000 \mathrm{U} / \mathrm{L}$, aspartate transaminase $415 \mathrm{U} / \mathrm{L}$, alanine transaminase $370 \mathrm{U} / \mathrm{L}$ ), an abdominal ultrasound that displayed a cystic mass at the level of the common bile duct (volume $=20 \mathrm{cc}$ ) and a computed tomography scan that showed markedly dilated and winding proximal biliary ducts along with a massive CDC (diameter nearly $5 \mathrm{~cm}$ ) displacing the portal vein and the mesenteric artery. Magnetic resonance cholangiopancreatography was carried out to confirm the diagnosis of type IA CDC according to the Todani classification. The patient underwent laparoscopic cholecystectomy, resection of the cyst and videoassisted hepaticojejunostomy with a Roux-en-Y loop. Prior to the procedure we performed a retrograde intraoperative cholangiopancreatography that confirmed a long common channel. Operative time was $4 \mathrm{~h}$ and $20 \mathrm{~min}$. After the procedure a nasogastric tube was left for 48 $\mathrm{h}$ and an abdominal drain was left for $7 \mathrm{~d}$. The postoperative course was uneventful with no major complications. The overall hospital stay was $14 \mathrm{~d}$. Laboratory tests were completely normalized after 1 month. Histological examination showed a CDC without malignancies and features of chronic cholecystitis. After 1 year of follow-up the child is asymptomatic with normal liver function.

\section{Case Report \#2}

A 4-year old girl came to our attention for recurrent abdominal pain in the past two months associated with acholic feces. Laboratory tests were normal except for hyperbilirubinemia $(1.8 \mathrm{mg} / \mathrm{dL})$. The abdomi- 
nal ultrasounds and magnetic resonance showed the presence of a type IB CDC according to the Todani classification with a diameter of $2 \mathrm{~cm}$. Surgical laparoscopic removal was therefore planned. We performed a laparoscopic cyst resection together with cholecystectomy and videoassisted hepaticojejunostomy with a Roux-en-Y loop. We left a nasogastric tube for $48 \mathrm{~h}$ and an abdominal drain for $7 \mathrm{~d}$. Operative time was 3 $\mathrm{h}$ and $50 \mathrm{~min}$. Histological examination confirmed the CDC. Laboratory tests were normal on the $6^{\text {th }}$ postoperative day. There was no any major complication. The child was discharged on the $11^{\text {th }}$ postoperative day and she was doing well eight months after surgery.

\section{Case Report \#3}

A female neonate was born at our hospital with an antenatal suspicion of CDC. Diagnosis was confirmed by postnatal abdominal ultrasound that revealed a cystic mass at the level of the common bile duct (major diameter $2.6 \mathrm{~cm}$ ) and by magnetic resonance cholangiopancreatography (type IA). Laboratory tests were normal. At 6 months of age, the patient underwent laparoscopic cholecystectomy, resection of the cyst and videoassisted hepaticojejunostomy with a Roux-en-Y loop. Operative time was $3 \mathrm{~h}$ and $20 \mathrm{~min}$. After the procedure, a nasogastric tube was left for $48 \mathrm{~h}$ and an abdominal drain was left for $7 \mathrm{~d}$. The postoperative course was uneventful with no major complications. The overall hospital stay was 14 d. Histology showed a CDC without malignancies and features of chronic cholecystitis. After 3 years of follow-up by abdominal ultrasound the patient is asymptomatic with normal liver function.

\section{Technique}

The procedure was performed with the patient in the lithotomy position and under general anesthesia. We used a $10 \mathrm{~mm}$ umbilical port for the camera, and four 3-5 mm operative ports (Figure 1). We performed the laparoscopic removal of the cyst and gallbladder (GB), video-assisted preparation of the Roux-en-Y loop and laparoscopic hepaticojejunostomy. First, the hepatoduodenal ligament was incised and the Calot triangle

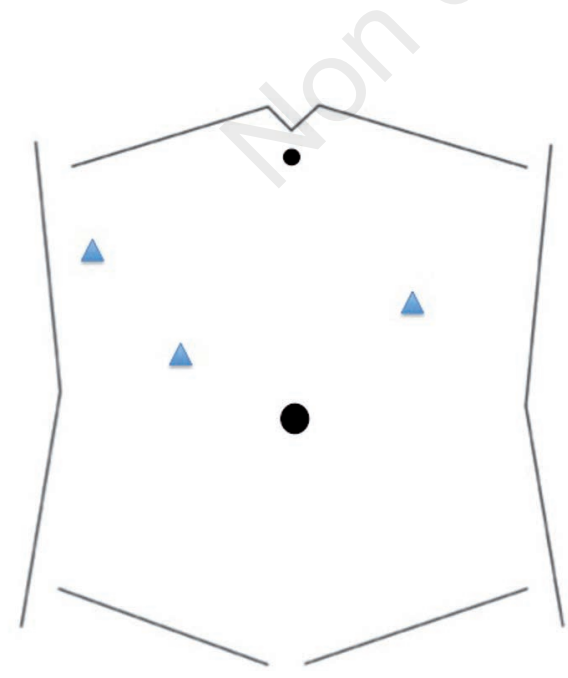

Figure 1. The lens is inserted by open technique at the umbilicus (circle). The 3-5 mm operating trocars (triangles) are placed under direct vision in the right and left hypocondrium and on the right anterior axillary line (hypocondrium). The hepatic retractor is inserted in the epigastrium (small circle). was exposed in order to start with the cystic duct and cystic artery dissection and subsequent ligation. The common bile duct was mobilized with hook cautery and the dissection proceeded over the tissues surrounding the bifurcation of the hepatic duct beyond the CDC (Figure 2). Enseal ${ }^{\circledR}$ (Ethicon, Johnson \& Johnson Medical, Somerville, NJ, USA) and Ligasure $^{\mathrm{TM}}$ (Covidien, Jersey City, NJ, USA) devices were used for the procedure. The common hepatic duct was ligated distal to the cyst. The inferior part of the common bile duct was ligated, as well, after its dissection from the pancreas and the identification of the distal end of the cyst and the pancreaticobiliary junction behind the duodenum (Figure 3). Once the GB had been dissected from the liver bed (Figure 4), it was removed through the umbilical wound along with the cyst. The tract of the jejunum located at nearly $20 \mathrm{~cm}$ far from the Treitz was extracted through the umbilical wound. A laparoscopic incision was performed on the bowel surface prior to the extraction to differentiate the proximal and distal part (Figure 5). The Roux-en-Y loop was created by end-to-side jejuno-jejunal anastomosis (Figure 6) and placed in the abdomen again. The jejunal loop was put through the right mesocolon that was subsequently closed. An end-to-side hepaticojejunostomy was intracorporeally established with interrupted 5-0 Vicryl (Figures 7 and 8).

\section{Results and Discussion}

Choledochal cysts are more prevalent in Asian than in western countries, according to the previous studies in Korea, Japan, and China.1,2,5 In children, the main symptoms of a CDC are the presence of a mass, jaundice, and perforation. ${ }^{2}$ However, with aging, the manifestation of a CDC can include stones, pancreatitis, and biliary tract cancer, including GB cancer. ${ }^{3}$ Farello and colleagues published the first case of a laparoscopic CDC excision in 1995.6 Since that time, an increasing number of institutions have adopted this technique, which can be performed safely among children, infants and newborns as well, with good success. ${ }^{7}$

Obviously, the experience of Asian pediatric surgeons in laparoscopic CDC excision is more extensive than that of Europeans for the higher prevalence of the disease in their countries. The attitude of those who approach for the first time to this type of minimally invasive approach should be to take a leaf from the vast experience of high volume centers in Asia (for instance Liem and Li).4,5

Laparoscopic excision of CDCs has been supposed to give better observation, a better cosmetic result, potentially less postoperative pain, and a shorter recovery. ${ }^{8} \mathrm{Jang}$ and colleagues described a four port technique in 2006. ${ }^{3}$ Laparoscopic CDC dissection and the hepaticojejunostomy are considered the most difficult steps of the procedure. ${ }^{5}$ The group of Long Li advocates the use of suspension stitches together with cyst aspiration to aid the dissection. ${ }^{5}$ In most series, the jejunojejunostomy is fashioned extracorporeally. ${ }^{8}$ The main argument for performing an extracorporeal anastomosis is that it decreases the operative time. Gander and colleagues reported that average operative times with total intracorporeal reconstruction were comparable to previously reported series of extracorporeal reconstructions. ${ }^{9}$ The minimal handling of the bowel by performing an intracorporeal jejunojejunostomy may minimize postoperative ileus that allows quicker postoperative feeding and earlier discharge. ${ }^{9}$

Intraoperative complications are possible and include injury of portal vein, transection of two hepatic ducts, injury of pancreatic duct, and Roux limb twist. It is preferable to resect the cyst in the first months of life to prevent cholangitis. ${ }^{10}$ Recurrent cholangitis may result in difficult dissections and increase the risk of intraoperative complications.

Early postoperative complications include bleeding, anastomotic leakage and pancreatic fistula, and intestinal obstruction. In the laparoscopic literature, the rate of bile leak has ranged from 0 to 


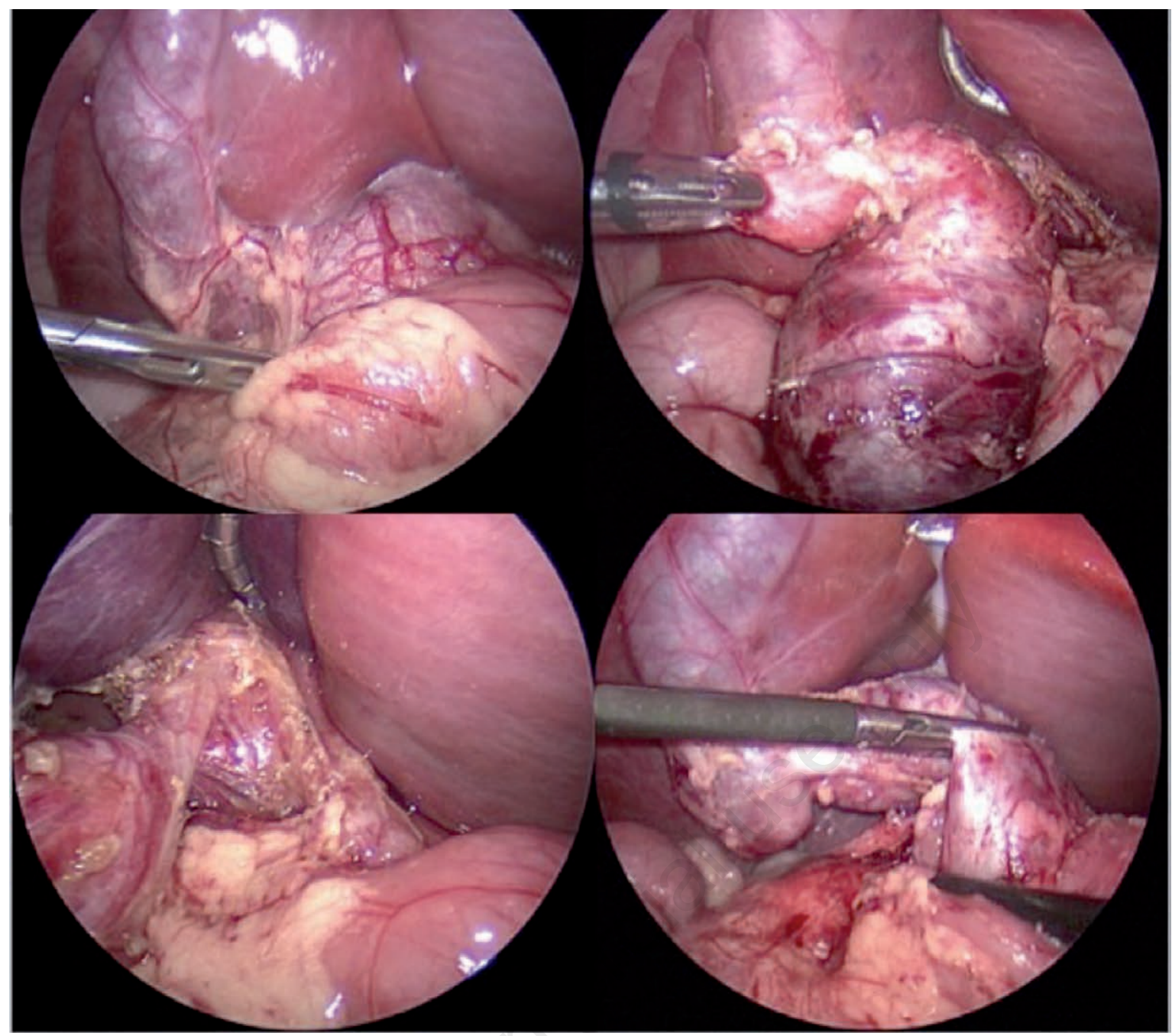

Figure 2. Hepatic duct exposition and dissection of the choledochal cyst using hook, bipolar dissector.

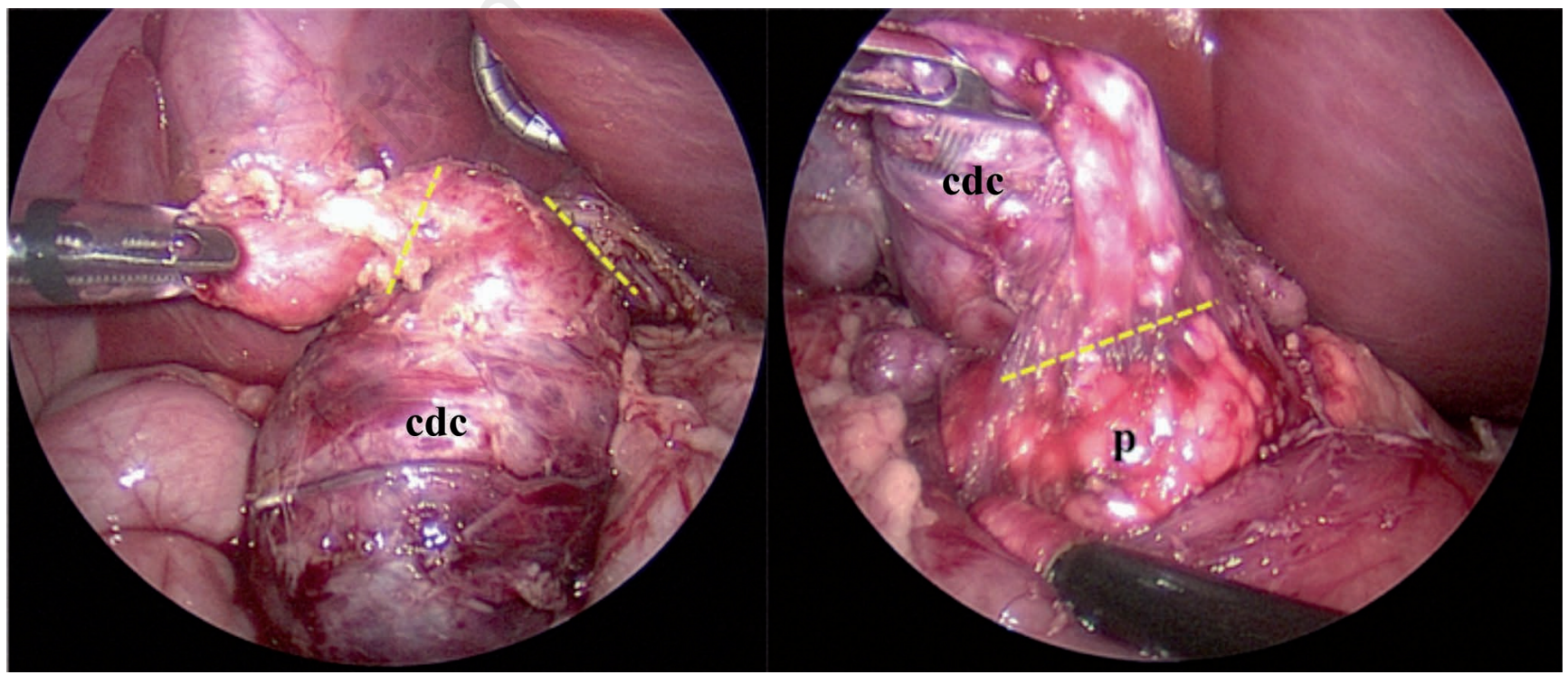

Figure 3. Dissection permits the isolation of the cyst from the surrounding structure. cdc=choledochal cyst; $p=$ pancreas; yellow interrupted lines=ligation sites. 


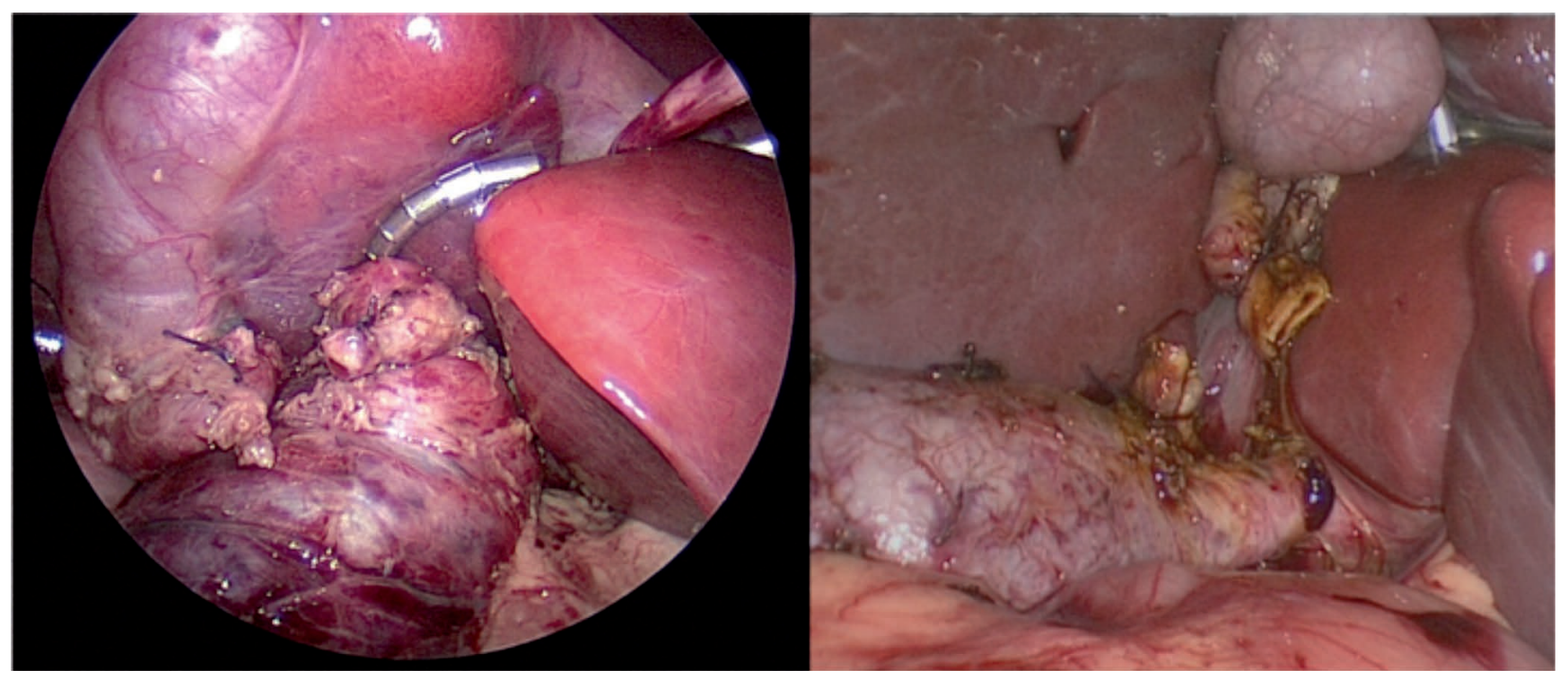

Figure 4. Disconnection from the liver bed.

20\%.5,11,12 Ure and colleagues reported a case of early small bowel obstruction at the eighth postoperative day, which required a minilaparotomy. ${ }^{13}$ Main late complications include cholangitis, anastomotic stricture, intrahepatic calculi, and bowel obstruction. Lee and colleagues reported one patient who developed a small bowel obstruction 3 years after the initial operation. ${ }^{8}$ Abdominal pain and pancreatitis due to leaving a remnant of the cyst in the pancreatic head were also mentioned. 14 The development of carcinoma in a retained CDC wall has been reported. 15 Therefore, it is recommended to completely remove the cyst at the level of the common biliopancreatic channel orifice at the distal end and approximately $5 \mathrm{~mm}$ from the confluence of the right and left hepatic ducts at the proximal end.7 The possibility of such serious late complications has made lifelong follow-up crucial.

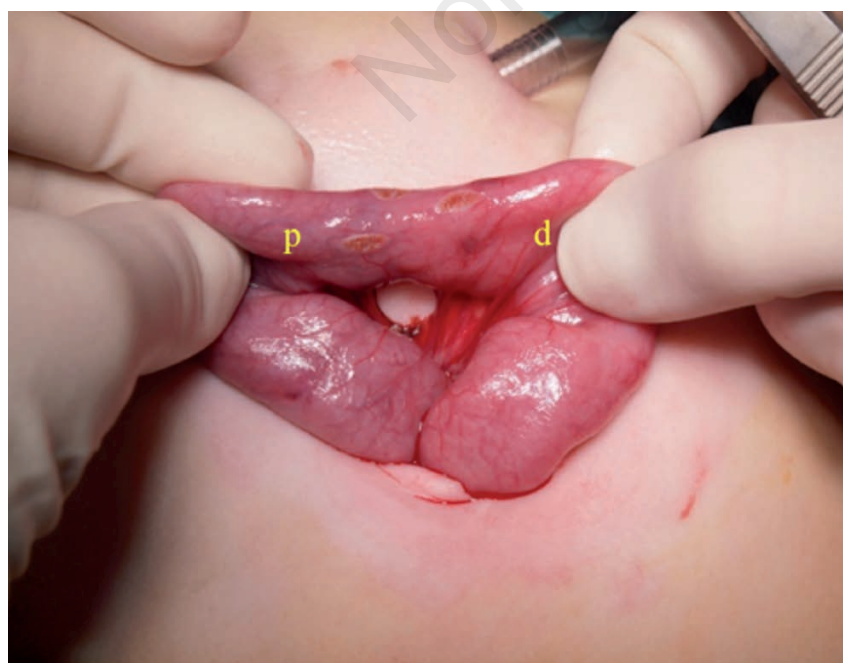

Figure 5. The jejunal loop was extracted through the umbilical wound. The proximal segment $(p)$ is distinguished from the distal one (d) thanks to the markers on the bowel surface.
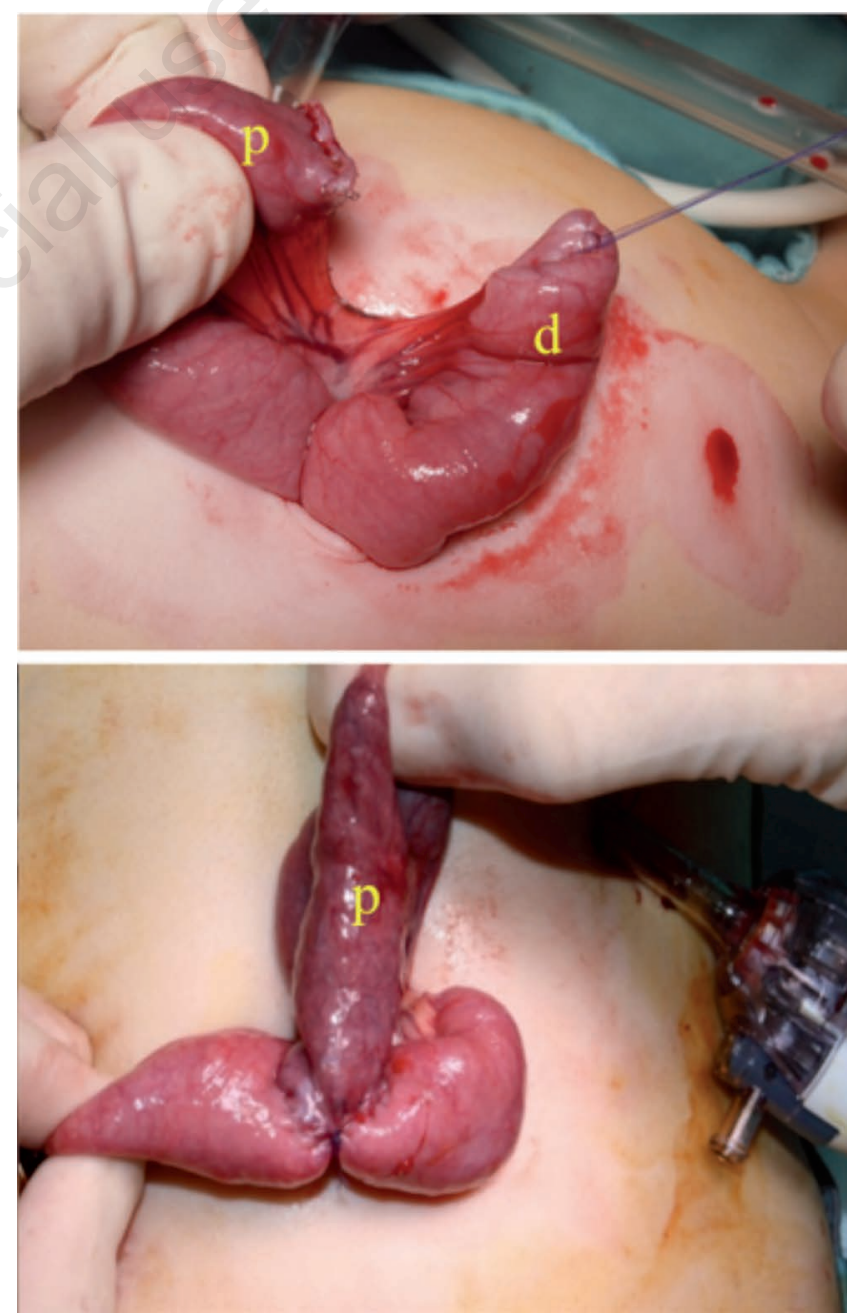

Figure 6. Roux-en-Y loop creation. $P=$ proximal part of the jejunal loop; $d$ =distal part of the jejunal loop. 


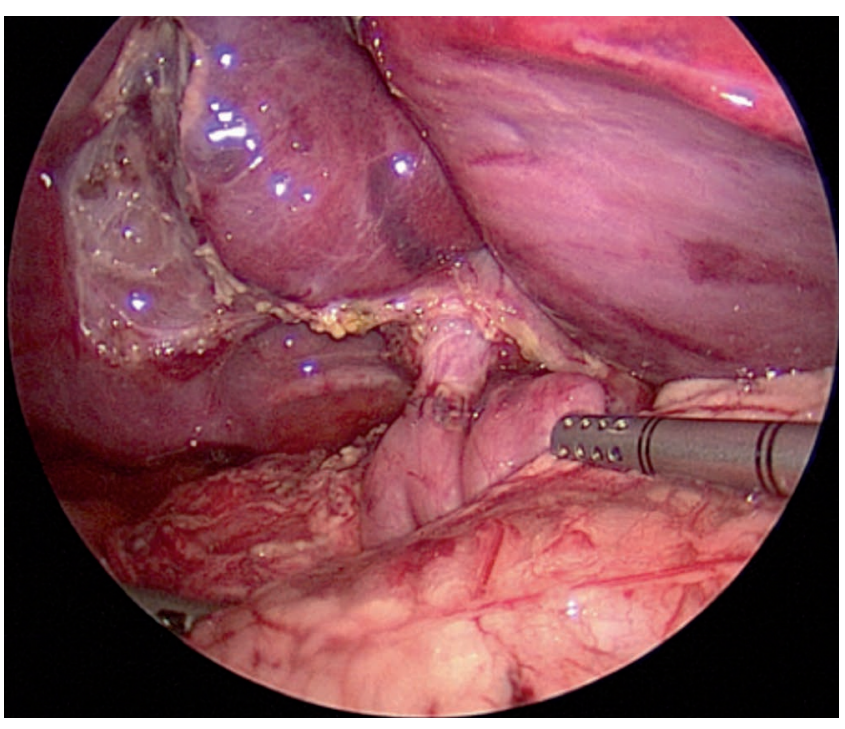

Figure 7. An end-to-side hepaticojejunostomy was performed laparoscopically at the end.

\section{Conclusions}

Laparoscopic excision of a CDC and hepaticojejunostomy with extracorporeal Roux-en-Y anastomosis can be done safely with good cosmetic and functional results. Considering the results of high volume centers in Asia together with our early experience, we recommend caution to prevent injury to the pancreatic duct and biliary structures during dissection and anastomosis. Lifelong surveillance is mandatory, even after resection of the CDC.

\section{References}

1. Miyano T, Yamataka A. Choledochal cysts. Curr Opin Pediatr 1997;9:283-8.

2. Jang JY, Yoon YS, Kang MJ, et al. Laparoscopic excision of a choledochal cyst in 82 consecutive patients. Surg Endosc-Ultras 2013;27:1648-52.

3. Jang JY, Kim SW, Han HS, et al. Totally laparoscopic management of choledochal cysts using a four-hole method. Surg Endosc-Ultras 2006;20:1762-5.

4. Liem NT, Pham HD, Dungle A, et al. Early and intermediate outcomes of laparoscopic surgery for choledochal cysts with 400 patients. J Laparoendosc Adv A 2012;22:599-603.

5. Li L, Feng W, Jing-Bo F, et al. Laparoscopic-assisted total cyst excision of choledochal cyst and Roux-en-Y hepatoenterostomy. J Pediatr Surg 2004;39:1663-6.

6. Farello GA, Cerofolini A, Rebonato M, et al. Congenital choledochal cyst: video-guided laparoscopic treatment. Surg Laparosc Endosc 1995;5:354-8.

7. Liem NT. Laparoscopic surgery for choledochal cysts. J Hepatobil Pancreat Sci 2013;20:487-91.

8. Lee KH, Tam YH, Yeung CK, et al. Laparoscopic excision of choledochal cysts in children: an intermediate-term report. Pediatr Surg Int 2009;25:355-60.

9. Gander JW, Cowles RA, Gross ER, et al. Laparoscopic excision of

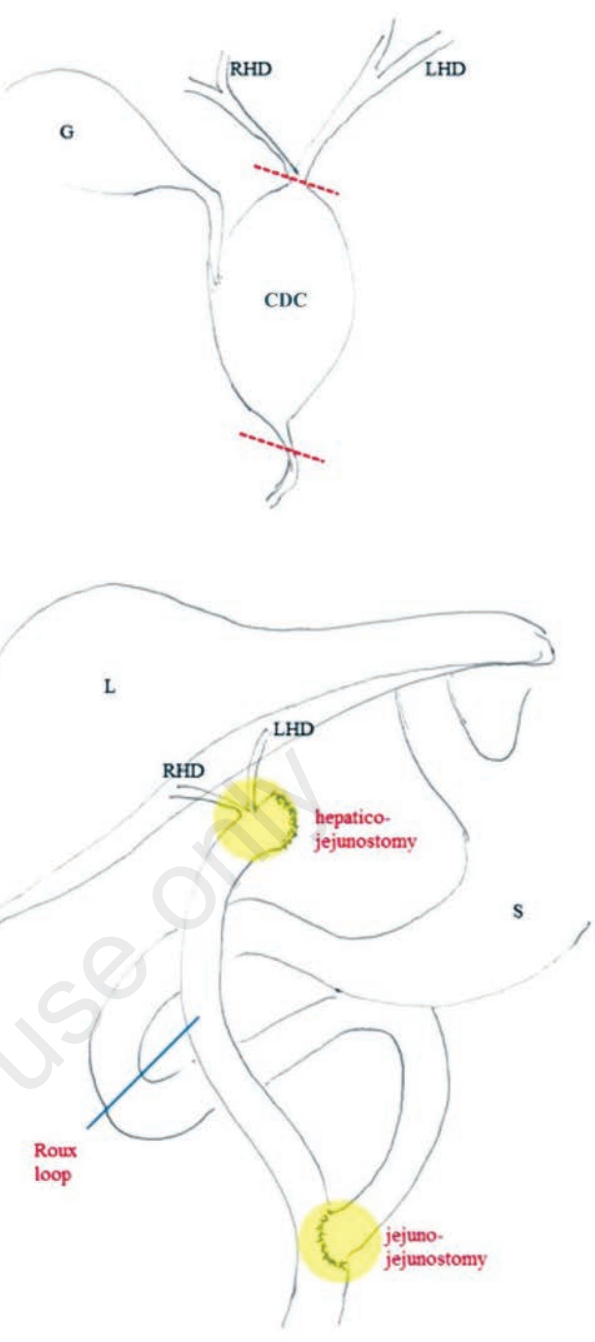

Figure 8. Schematic presentation of surgical procedure. RHD=right hepatic duct; $L H D=$ left hepatic duct; $C D C=$ choledochal cyst; $\mathrm{G}=$ gallbladder; $\mathrm{L}=$ liver; $\mathrm{S}=$ stomach. Left panel, preoperative; right panel, postoperative.

choledochal cysts with total intracorporeal reconstruction. J Laparoendosc Adv A 2010;20:877-81.

10. Ure BM, Nustede R, Becker H. Laparoscopic resection of congenital choledochal cyst, hepaticojejunostomy, and externally made Rouxen-Y anastomosis. J Pediatr Surg 2005;40:728-30.

11. Chokshi NK, Guner YS, Aranda A, et al. Laparoscopic choledochal cyst excision: lessons learned in our experience. J Laparoendosc Adv A 2009;19:87-91.

12. Srimurthy KR, Ramesh S. Laparoscopic management of pediatric choledochal cysts in developing countries: review of ten cases. Pediatr Surg Int 2006;22:144-9.

13. Ure BM, Schier F, Schmidt AI, et al. Laparoscopic resection of congenital choledochal cyst, choledochojejunostomy, and extraabdominal Roux-en-Y anastomosis. Surg Endosc 2005;19:1055-7.

14. Koshinaga T, Hoshino M, Inoue M, et al. Pancreatitis complicated with dilated choledochal remnant after congenital choledochal cyst excision. Pediatr Surg Int 2005;21:936-8.

15. Watanabe Y, Sato M, Tokui K, et al. Laparoscope-assisted minimally invasive treatment for choledochal cyst. J Laparoendosc Adv A 1999;9:415-8. 